\title{
The Effect of Strategic Management on the Organizational Performance Using the Balance Scorecards Approach to Measure Performance: A Case Study in the Nursing Department at Al-Khalidi Hospital and Medical Center
}

\author{
Dina Mohamed Said Qarah Qarashay ${ }^{1} \&$ Feras Ali Alzu'bi ${ }^{2}$ \\ ${ }^{1}$ Faculty of Pharmacy and Medical Sciences, Medical Health Center, Petra University, Jordan \\ ${ }^{2}$ Faculty of Business and Finance, Department of Management, The World Islamic Sciences and Education \\ University (WISE), Jordan \\ Correspondence: Feras Ali Alzu'bi, Faculty of Business and Finance, Department of Management, The World \\ Islamic Sciences and Education University (WISE), Jordan. E-mail: falzubi@gmail.com
}

Received: December 24, 2017

doi:10.5539/ijbm.v13n4p259
Accepted: February 22, $2018 \quad$ Online Published: March 18, 2018

URL: https://doi.org/10.5539/ijbm.v13n4p259

\begin{abstract}
Organizations nowadays are increasingly impracing in using strategic management to improve their performance, this study has mainly focused on the impact of the strategic management on the performance of Al Khalidi Hospital and Medical Center (KHMC), based on the using of the Balanced Scorecard as a measuring tool, regression analysis results Indicates the existence of a strong positive impact of strategic management on performance.

The main findings in this study that the internal process perspective is the most affected perspective in the strategic management, and that the strategic management have a positive impact on the performance in (KHMC). The four perspective of the balanced score card is an effective tool to measure the performance by objective achievement.
\end{abstract}

Keywords: balance scorecards, performance, Al- Khalidi Hospital \& Medical Center (KHMC), nursing department

\section{Introduction}

Strategic Management became the most important basic features in the success of any organization, projects or business, and it help to build a base essential to develop and measure performance, Strategic Management is a System of integrated processes related to strategic analysis and emanating from the organization's vision, mission until reach to the organization goals in growth and continuity and get a competitive advantage(Al-haj Mohammad, 2011).

Strategic Management outlines the concept of transmission of the institution from the administrative practices based on the mood of the individual, the random, routine, obviousness, intuition and tradition to the administrative practices that depend on participate (The team) and the planned change and innovation, initiative and invested in new technology and using renewable information in addition to the adoption of scientific research and experimentation as a stepping stones that essential for the development, and that is from the perspective that the management is a science that has its theories and principles and be exercised only by those who have prepared a special setting and received a professional license to practice. (Al-Khatib, 2001, p. 169).

"As a final step for the application of strategic management, is to work on the validation of the progress of the strategic management by evaluating the performance of the strategy through a review of internal and external factors that have adopted the strategy and measure performance and take corrective action.

In measuring institutional performance, we can use the concept of the Balanced Scorecard. "The value of the "balance scorecard" in recognizing how the interests of a variety of stakeholders can be interrelated" (Dessetal., 2012, p. 147)

"Robert S. Kaplan and David P. Norton proposed Balanced Scorecard concept to develop a benchmark of 
financial and non-financial. The advantages of the Balanced Scorecard are the approaches that seek to translate the mission and strategy into operational objectives, with the Balanced Scorecard, business unit performance measurement is not only expressed in financial measures but towards further elaboration into measures to encourage business units to create value for the company that is now and in the future. In addition to improving the internal capabilities such as the effectiveness of investment in human resources, systems and procedures are needed to obtain better performance in the future".(Fattah \&Syaripudin, 2016). The balanced scorecard supplemented traditional financial measures with criteria that measured performance from three additional perspectives - those of customers, internal business processes, and learning and growth, which they applied to measure performance in Al Khalidi Hospital and Medical Center (KHMC).

\subsection{Study Problem}

Problem of the study arose through the need to determine the impact of strategic management on the performance of the organizations and the extent to which managers involved in strategic planning are affected by the results of the planning and how they find the effect on the performance of the organization.

Recently, many organization start using the balanced score card in strategic management and to evaluate the performance of their strategic plans to determine where they are and how they will be, and therefore we can formulate the problem of the study by the following questions:

- Does the using of strategic management improve the organizational performance?

- How can the Balanced Score Card define the level of performance from its four perspective and how it will be reflected on the top management whom involved in the strategic planning?

\subsection{Importance of the Study}

This study is focusing on the linking between the performance measurements and the desirable results of strategic planning through applying the balanced score card system that measure the performance from four perspectives, financial, learning and growth, internalprocesses, and customer and stakeholders.

Most of studies are evaluate the performance according to the financial perspective; the researcher used the BSC as a more comprehensive tool to measure the entire performance according to how much the firm can achieve its goals.

Kaplan \& Norton proposed a general framework to enhance performance management system and to govern the consistency and quality of processes within organizations. The start point was to answer the following questions related to the four perspectives:

1. To achieve vision how must the organization learn and improve?

2. To satisfy customers, at which processes must organization excel?

3. To achieve vision how must the organization looks to its customers?

4. If we Succeed, How will the organization looks to its shareholders?

\subsection{Objective of the Study}

The aim of this study is to identity the effect of applying strategic management using the balanced score card which measure and evaluate the organization performance that it use Balanced Scorecard (BSC) as a valid and well-focused approach to measure the effectiveness of all the used procedures and activities. It is an Integrated Management System that consists of three components:

1) Strategic Management System.

2) Communication tool, and

3) Performance Measurement System.

This study is aim to examine the effectiveness of the third component according to the perspectives of:

- Financial perspective

- Learning and growth perspective

- Internal processes perspective

- Customer and stakeholders' perspective.

\subsection{The Study Model}

This study is to investigate the improving impact of the strategic management on the organization performance 
using the $\mathrm{BSC}$ as a tool to measure the performance, the Figure below illustrates the relationship between independent and dependent variables.

Independent Variables

Dependent Variable

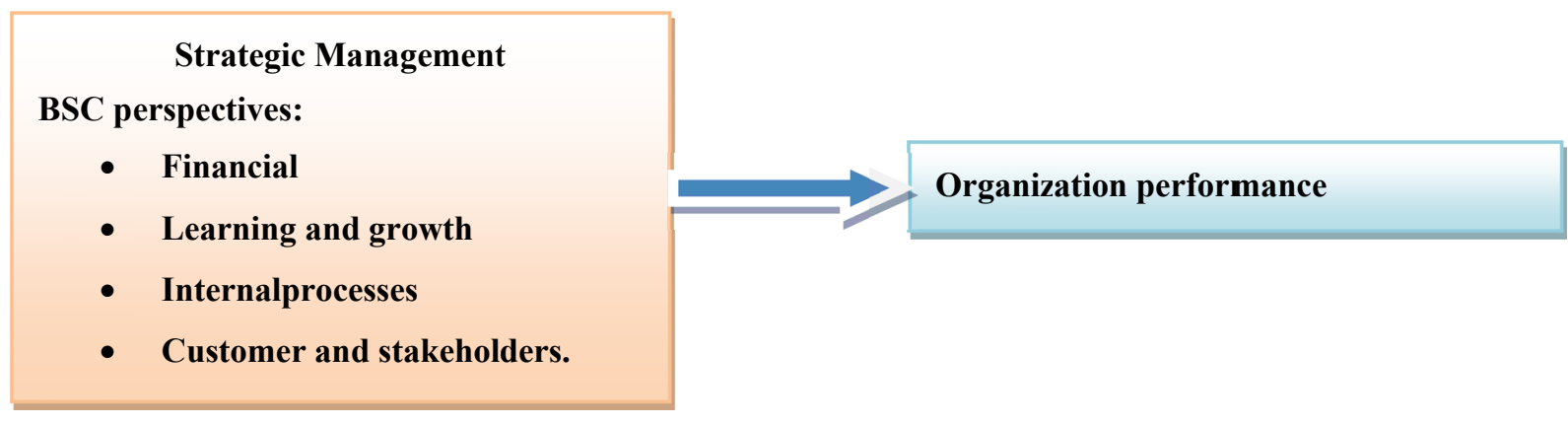

\section{Hypothesis}

The research aims to test the level of performance after applying the BSC as a strategic management tool to find the extent to which the role of the four perspective, namely; financial, learning and growth, internal processes, customer and stakeholders., play in the measuring the performance.

\subsection{Main Hypothesis}

Ho: The Strategic Management doesn't have an effect on Organizational Performance.

\subsection{Sub Hypotheses}

Ho-1: The Strategic Management doesn't have an effect from the financial perspective of BSC on Organizational Performance.

Ho-2: The Strategic Management doesn't have an effect from the Customer perspective of BSC on Organizational Performance.

Ho-3: The Strategic Management doesn't have an effect from the Internal Processes perspective of BSC on Organizational Performance.

Ho-4: The Strategic Management doesn't have an effect from the Learning and Growth perspective of BSC on Organizational Performance.

\section{Previous Studies}

Vesty and Brooks (2017) study entitled: "St George Hospital: "Flexible Budgeting, Volume Variance, and Balanced Scorecard Performance Measurement"

This study deals with funding, budgeting, and performance measurement in public hospitals. Data from the Orthopedic Unit at St George Hospital is used to examine efficiency and effectiveness of management in meeting budgeted targets.

The result was that monitoring efficiency and effectiveness of hospitals is an important priority for the government. The goal is to motivate hospital managers toward achieving costs that match, or are lower than, funds received, without affecting quality of care. Quality of care also relates to timeliness of treatment, patient length of stay, and avoidance of long waiting lists (capacity management). To meet these contractual obligations, a hospital is therefore required to utilize all allocated Weighted Activity Cost Unit (WACUs).

Fattah \&Syaripudin (2016) study entitled: "Philosophical Business Performance Competition on the Balance Scorecard Approach".

The purpose of this study was generally to answer the problem formulation grains, namely: 1) To analyze philosophically how the Balanced Scorecard through financial and non-financial perspectives (customer, internal business process and learning and growth) is used to assess the performance of the Human Resources companies as part of the company's business strategy; 2) To analyze philosophically how the influence of Non-Financial perspectives (customer, internal business process and learning and growth) affect the performance of the company's corporate Human Resources.

The study found that the perspective of learning and growth of compensation indicator indicates that the compensation received by employees in the form of salaries and allowances and a maximum deemed not to be 
scaled back so that employees can be more motivated to work. In addition, indicators of skills and employability (competency) of employees as well as the involvement and active participation of employees and career development within the company have been considered relatively.

SaadandDaraghma (2016) study entitled: "Using of the Balanced Scorecard for Performance Evaluation: Empirical Evidence from the Listed Corporations in the Palestine Exchange (PEX)".

This paper is aiming at testing the extent to which the listed Palestinian corporations in the Palestine Exchange (PEX) are using the four perspectives of the Balanced Scorecard (BSC) in evaluating the performance.

The findings of this paper state the following points: (1) The financial managers rely on the financial and customer perspectives for evaluating the performance of the listed corporations in the PEX. (2) The Palestinian listed corporations do not rely on the learning and growth indicators for measuring the performance. (3) The Palestinian listed corporations do not rely on the business process indicators for measuring the performance. (4) This paper concludes that the listed corporations in Palestine do not rely on the BSC indicators for measuring the performance in a correct and complete way.

\section{What distengwesh this study}

What distengwesh this study is that it measure the performance of all procuresses and activities depending on the measuring tool (BSC) using the four perspectives of them, and the progress for five years.

\section{The Methodology of the Study}

In order to achieve the objectives of the study and testing of hypotheses we select the descriptive analytical method, by reference to the following sources of data:

1- Secondary sources: include survey of the previous theoretical studies relevant to the subject of the study.

2- Primary sources: included the design and distribution of the questionnaire on the study sample in order to gather data about the views category covered.

Statistical analysis software (SPSS) used for the purposes of statistical analysis of the data collected.

\subsection{The Study Population}

The study conducted within Al Khalidi Medical Center and the population was focused on the nursing department, the sample we choose to study consists of the top and middle level of management.

The case sample number is 32 from the total population that is 35 .* $^{*}$

* (Reaserch Method for Business, UMA SEKARAN \& ROGER BOUGIE,2010).

\subsection{Literature Review}

Strategic Management consist of the analysis, decisions and actions an organization Undertakes in order to create and sustain competitive advantages over a lengthy period of time, that mean focusing on two fundamental questions:

- How should we compete in order to create competitive advantages in the market place?

- How can we create competitive advantages in the market place that are unique, valuable, and difficult for rivals to copy or substitute?

The process of obtaining the competitive advantage is related to an organized steps of management that strategically start with the vision and mission until achieving goals, according to the definition of (David, 2011) of strategic management that "it is an art \& science of formulating, implementing, and evaluating, cross-functional decisions that enable an organization to achieve its objectives" (David, 2011, 6), this definition lead us to the main three stages of the strategic management steps: Strategy formulation, Strategy implementation, Strategy evaluation.

Strategy formulation include developing a vision and mission, performing SWOT analysis (strength, weaknesses, opportunity, and threats), establishing long-term objectives, choose the best from alternative strategies.

"Pearce11 \& Robinson (2011) suggest the risks of strategic management, that managers must be trained to guard against three types of unintended negative consequences of involvement in strategy formulation:

1-The time that managers spend on the strategic management process may have a negative impact by scheduling their duties to allow the necessary time for strategic activities.

2-If the formulators of strategy are not intimately involved in it's implementation, they may shirk their individual responsibility for the decisions reached. Thus, strategic managers must be trained to limit their promises to 
performance that the decision makers and their subordinates can deliver.

3-Strategic managers must be trained to anticipate and respond to the disappointment of participating subordinates over unattained expectations. Subordinates may expect their involvement in even minor phases of total strategy formulation to result in both acceptance of their proposals and an increase in their rewards, or they may expect a solicitation of their input on selected issues to extend to their areas of decision-making.

Sensitizing managers to these possible negative consequences and preparing them with effective means of minimizing such consequences will greatly the potential of strategic planning”.( Pearce11 \& Robinson, 2011,11).

Strategy implementation include Developing a strategy-supportive culture, Creating an effective organizational structure, Redirecting marketing efforts, Preparing budgets, Developing and utilizing information systems, and Linking employee compensation to organizational performance.

Strategy evaluation is the final stage, Managers desperately need to know when particular strategies are not working well; strategy evaluation is the primary means for obtaining this information. All strategies are subject to future modification because external and internal factors are constantly changing. Three fundamental strategy-evaluation activities are (1) reviewing external and internal factors that are the bases for current strategies, (2) Measuring performance, and (3) taking corrective actions. Strategy evaluation is needed because success today is no guarantee of success tomorrow! Success always creates new and different problems; complacent organizations experience demise.

"Pearce11 \& Robinson (2011) suggest the benefits of Strategic Management, whenusing the strategic management approach, managers at all levels of the firm interact in planning and implementing. As a result, the behavioral consequences of strategic management are similar to those of participative decision-making. Therefore, an accurate assessment of the impact of strategy formulation on organizational performance requires not only financial evaluation criteria but also nonfinancial evaluation criteria-measures of behavior-based effort. Several behavioral effects of strategic management improve the firm's welfare:

1-Strategy formulation activities enhance the firm's ability to prevent problems. Managers who encourage subordinates' attention to planning are aided in their monitoring and forecasting responsibilities by subordinate who are aware of the needs of strategic planning.

2-Group-based strategic decisions are likely to be drawn to be from the best available alternative. The strategic management process results in better decisions because group interaction generate a greater variety of strategies of group members improve the screening of options.

3-The involvement of employees in strategy formulation improves their understanding of the productivity reward relationship in every strategic plan and, thus, heightens their motivation.

4-Gaps and overlaps in activities among individuals and groups are reduced as participation in strategy formulation clarifies differences in roles.

5-Resistance to change is reduced. Though the participants in strategy formulation may be no more pleased with their own decisions than they would be with authoritarian decisions, their greater awareness of the parameters that limit the available options makes them more likely to accept those decisions".( Pearce11 \& Robinson, 2011, 9-11).

In this study we will focus on the third stage to measure the effective impact of the strategic management on the performance of the organization.

In order to measure the performance of the organization we will use the Balanced Score Card (BSC) as a strategic tool for applying the strategic plan and measuring the performance. "The balance scorecard is not only a management system, it enables companies to clarify their strategies, translate them into action, and provide meaningful feedback around both the internal business processes and external outcomes in order to continuously improve strategic performance and results". (Pearce11 \& Robinson, 2011, 363).

In January 1992 Robert S. Kaplan and David P, Norton introduce the Balanced Score Card in a paper entitled "the Balanced Score Card: measures that drive performance" in Harvard Business Review.

The traditional financial accounting measures (return on investment and earnings-per-share) was giving an unobvious perspective to measure the organizational performance and doesn't give a comprehensive measure for performance. So the BSC concept become as a solution for this dilemma because it balances between more comprehensive perspectives of performance.

The Balance Scorecard balances and link between: 
- Financial \& non-Financial indicators.

- Tangible \&intangible measures.

- Internal \& eternal aspects.

- Performance drivers (Leading) \& outcomes (Lagging).

The Balance Scorecard Converts strategy into an integrated system defined across four business perspectives.

\section{1-Financial:}

"To satisfy our shareholders, what financial objectives must we accomplish?"

\section{2-Customer:}

"To achieve our financial objectives, what customer needs must we serve?"

\section{3-Internal:}

"To satisfy our customer, and shareholders in which internal business must we excel?"

\section{4-Learning \& Growth:}

"To achieve our goal, how must our organization learn and innovate?"

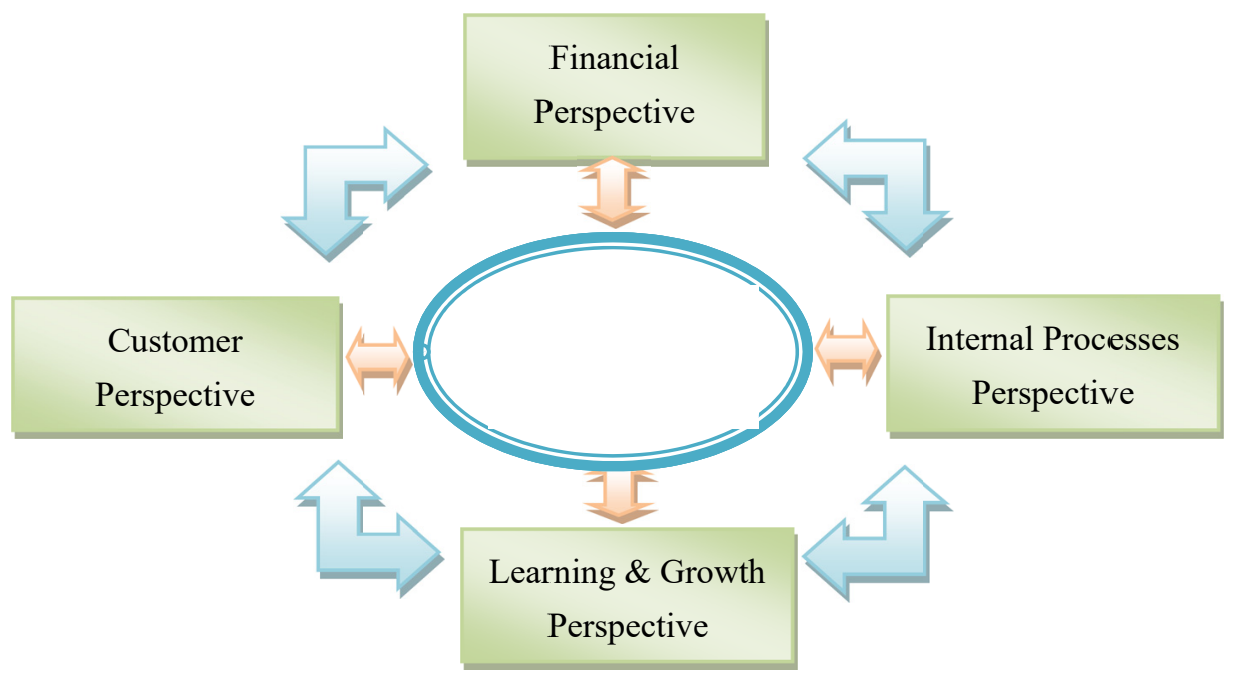

Figure 1. BSC perspectives

Source: Kaplan \& Norton (1996) (with some modifications).

"Dess etal. (2012) suggest that the balance scorecard concept is a useful and an appropriate management tool. However, there are many potential limitations, that may short- circuit its value, including the following:

1-Lack of a clear strategy.

2-Limited or ineffective Executive sponsorship.

3-Poor data on actual performance.

4-Inappropriate links of scorecard measures to compensation.

5-Inconsistent or inappropriate Terminology". (Dess, etal., 2012, 150)

This study is applied on AL- Khalidi Hospital and Medical Center (KHMC), the BSC used to measure the performance from the four perspective to define the impact of the strategic management.

\subsection{AL- Khalidi Hospital and Medical Center}

Originally established in 1978 as a maternity hospital, KHMC today stands amongst the leading heart and comprehensive specialty hospitals in Jordan, building on the 30 years of medical expertise, research and development. The steadfast commitment towards medical excellence and advancement has placed KHMC as a principal hospital in the region offering a multitude of highly specialized medical and surgical procedures as well as performing pioneering medical techniques unobtainable within the region. Amongst the Center's strongholds 
are the ICCU unit and the highly-specialized Intensive Stroke Unit, considered as the largest in the private sector in Jordan. Furthermore, KHMC boasts seven new operating theaters, which have recently been modernized and re-equipped with the very latest equipment and cutting-edge operating room systems in addition to a 24-hour pharmacy and emergency wards fully equipped for minor surgeries, cardio-pulmonary resuscitation and minor orthopedic surgery rooms alongside an observation area offering the best possible emergency services. Complementary to our emergency services is KHMC's highly trained and specialized paramedic team and ambulance cars available and operating 24 hours a day.

From this perspective KHMC focus on the strategic planning to improve it's medical service as a competitive advantage around the region, and KHMC implement all the requirements of strategic planning starting with vision mission and SWOT analysis (Strengths, Weaknesses, Opportunities \& Threats), in addition to the strategic plan until reaching to the final stage of evaluating the performance.

Connecting Al Khalidi Hospital and Medical Center (KHMC's) components of skills, expertise, talents \& advanced technology, in a seamless \& patient-centered way, has been its promise since its inception over 30 years ago $\&$ as a result it blossomed into the iconic institute of comprehensive healthcare services as it is today.

This Strategic Plan has been developed to clarify Al Khalidi Hospital and Medical Center's directions from 2011 to 2013. It provides a framework for the planned development \& performance improvement foreseen by KHMC's Board of Directors \& management. It is a declaration of KHMC's aspirations, the envisioning of our desired future status, as well as the means by which to achieve it.

This plan demonstrates the route which KHMC will be following to develop \& transfer itself to the location set by KHMC's Board of Directors as represented by KMC's Mission, Vision, Values and Directions.

-KHMC Mission:We, Al Khalidi Hospital and Medical Centre, a heart \& comprehensive specialty hospital, are committed to service excellence, patient safety \& continuous performance improvement. Earned the status of being amongst the best in patient satisfaction in the healthcare sector in the region. We strive to be a firm supporter of staff training $\&$ to achieve optimal use of the latest technology $\&$ its applications.

-KHMC Vision: To be the premier regional provider of superior healthcare services in the private sector.

-KHMC Values: We at KHMC hold these values to be fundamental:

Respect: We respect each person as a member of the hospital community. Involvement \& teamwork determine our future.

Service Excellence: We are committed to our standards of service excellence \& dedicated to exceeding the expectations of those we serve.

Responsibility:We accept personal accountability for the work we do.

Communication: We promote open communication that fosters partnership \& enhances timely, effective \& appropriate responses.

Innovation: We are committed to a supportive environment that encourages new ideas \& creativity.

\section{KHMC Strategic Analysis}

In order to identify KHMC's directions for improvement, development, setting priorities, defining quantified objectives \& setting action plans, KHMC has delivered a comprehensive SWOT analysis of its business situation. Results of the SWOT Analysis are provided hereafter:

\begin{tabular}{ll}
\hline Strengths & Weaknesses \\
\hline Distinguished reputation of the history of service quality. & $\begin{array}{l}\text { Institutional stability that leads to resistance to } \\
\text { change/development. } \\
\text { Lack of continuous \& hospital-wide capacity building programs. } \\
\text { Small segment of the local market is targeted. } \\
\text { Owners are involved in the day-to-day activities. }\end{array}$ \\
Pioneers in introducing new technologies \& procedures. & $\begin{array}{l}\text { Lack of international recognition (official accreditation like JCIA, } \\
\text { Certificates of Excellence...etc). }\end{array}$ \\
Distinguished medical staff \& health care providers. & $\begin{array}{l}\text { Lack of tools adopted for performance benchmarking. } \\
\text { Effectively integrated administrative \& managerial systems. }\end{array}$ \\
Ability to attract high caliber professionals. & $\begin{array}{l}\text { Lack of medical data analysis \& interpretation } \\
\text { Records). Medical }\end{array}$ \\
Wide list of reputable physicians. & Need to motivate employees' creative thinking/innovation. \\
Good infrastructure. & Lack of space \& limited number of beds.
\end{tabular}


Promotion \& media coverage.

In-house service centers (e.g. IT, Maintenance, Kitchen, etc.).

Opportunities

New regional \& international markets potential.

Threats

Competing medical centers are achieving international recognition.

Franchising.

Shortage of qualified human resources in the local market.

Attracting insurance companies.

Developing KHMC insurance system.

Large health care centers with higher capacities.

Develop coalitions with external/foreign parties.

Increasing costs.

Insurance companies policies.

International recognition of the level of health care service in Access to the center (heavy traffic).

Jordan.

Performance improvement through partnerships with local Protective regulations against patient's financial default.

community.

Compliance (recognition) with international standards.

Relatively high turnover.

Develop local community service programs.

Another new big health care centers opening.

Source:(KHMC Nursing Department).

KMC's Strategic Plan

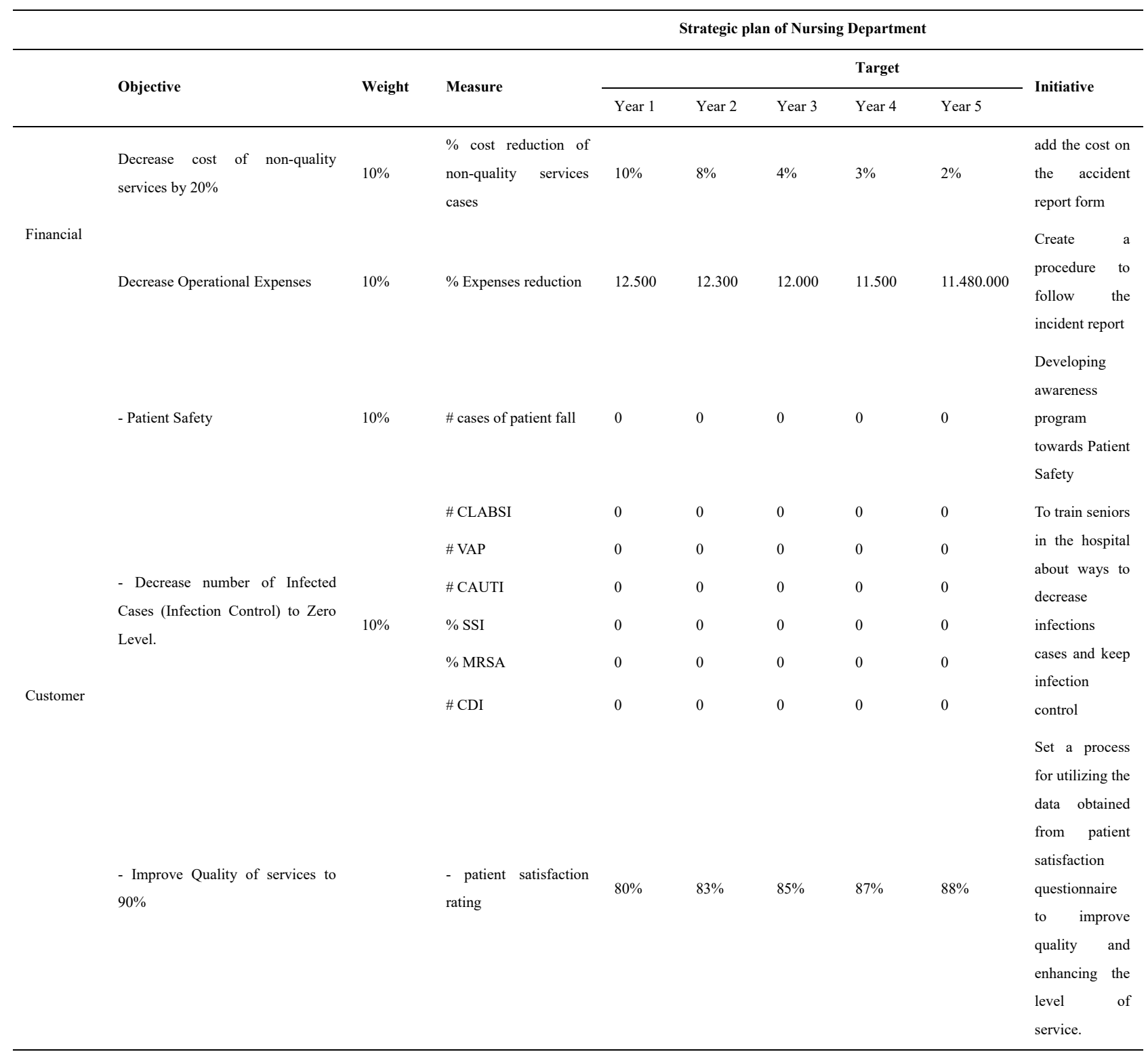




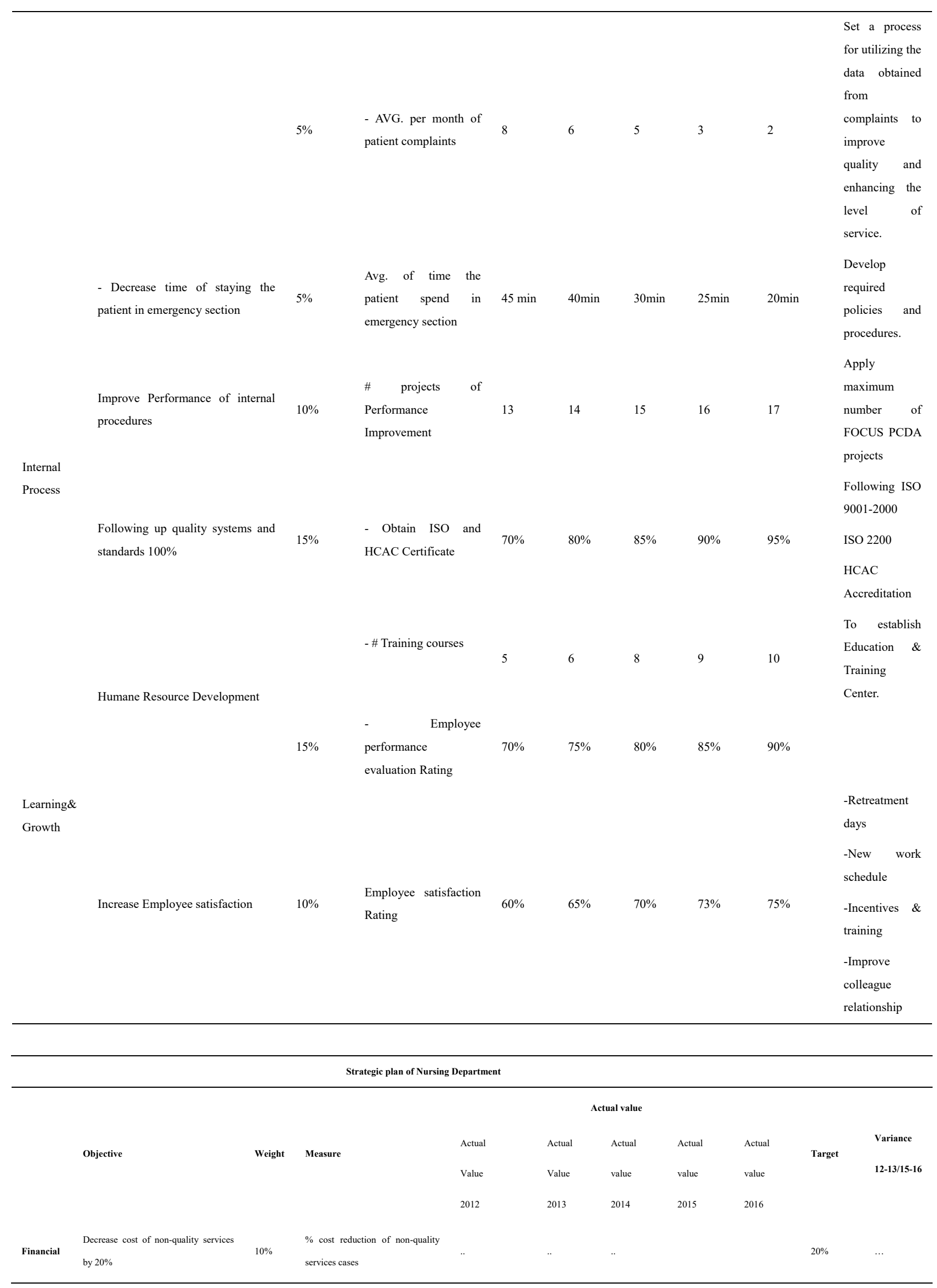




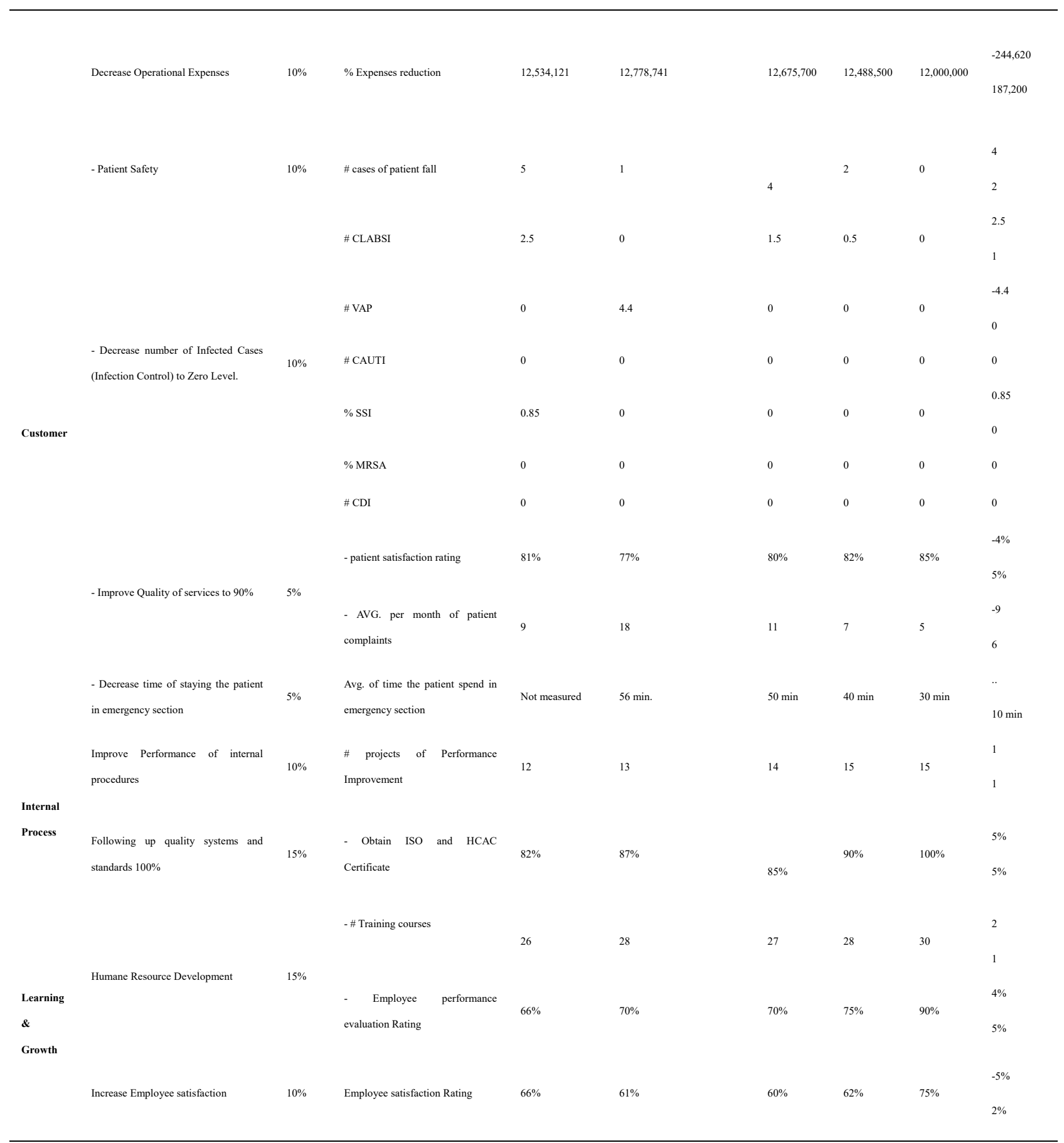

CLABSI: Central Line Associated Blood Stream Infection;

CAUTI: Catheter Associated Urinary Tract Infection;

MRSA: Methicilline Resistant Staph Aureus;

VAP: Ventelator Associated Pneumonia;

SSI: Surgical Site Infection;

CDI: Clostridum Deficit Infection. 
Patient Complaints by Department

\begin{tabular}{lllll}
\hline DEPT & 2013 FEB & 2014 FEB & 2015 FEB & 2016 FEB \\
\hline Admission office & 5 & 8 & 6 & 5 \\
Nursing & 9 & 18 & 19 & 14 \\
Physicians & 1 & 3 & 3 & 2 \\
Food service & 1 & 2 & 3 & 2 \\
Houskeeping & 3 & 2 & 1 & 2 \\
Ancillary(ER, Lab, radiology) & 2 & 4 & 3 & 3 \\
Maintenance & 3 & 2 & 2 & 3 \\
Others & 7 & 5 & 5 & 4 \\
\hline
\end{tabular}

According to the previous data, using the data integrated from KHMC, the researchers created a Balanced Scorecard to review the historical results, confirmed that the cross result had varied over the next year, and explored the variance to discover the source of the problem.

The financial perspective include one objective that has not measured as an indicator for the current plan that refers to the change in the top management of the nursing department. Later we noticed a clear developments in the other perspectives of BSC.

The customer perspective indicates a negative indicators in general:

1. Patient Safety indicators results in positive effects.

2. Decrease number of Infected Cases (Infection Control) to Zero Level: this objective indicators include positive and negative results that the negative results was in VAP (ventilator associated pneumonia) that implies the inadequate care for the ventilator equipment. But later on (2015-2016) it has been decreased to Zero level. Also the indicator for CLABSI ( Central Line Associated Blood Stream Infection), we noticed that the result has decreased from 2.5 to 1 .

3. Improve Quality of services to $90 \%$ : this objective indicators give a positive results.

4. Decrease time of staying the patient in emergency section: average for the indicator of this objective was taken for the last 5 months of the year 2013, and continue during 2015 to 2016 with positive result.

- The Internal Processes perspective indicates a positive indicators in general.

- The Learning and Growth perspective was neglected and didn't show an important improvement during 2013-2014, but from that on, more concentration was taken on training, employee development and employee empowerment, to increase employee satisfaction, which transfer from negative to positive results.

\section{The Analysis Result}

The main findings in this study that the internal process perspective is the most affected perspective in the strategic management, and that the strategic management have a positive impact on the performance in (KHMC). The four perspective of the balanced score card is an effective tool to measure the performance by objective achievement.

\subsection{The Conclusion}

The findings and the analysis indicate that the strategic management have a positive impact on the performance in KHMC. The four perspective of the balanced score card is an effective tool to measure the performance by objective achievement.

\subsection{Recommendations}

1. KHMC must increase the concern about decreasing the cost, and give more attention to the process of measuring the expenses.

2. It is necessary to evaluate the employees and use the evaluation analytics as a feedback in the improvement process including the motivation and incentives to decrease the employee turnover.

3. It is important to increase the quality of service and customer satisfaction as a competitive advantage to attract the customer.

4. KHMC must distribute its concern on the four perspectives without focusing on one area and forgetting other areas. 


\subsection{Future Works}

1. To extent this study by including other private hospitals to use the BSC to measure the impact of strategic management on their performance.

2. Use the BSC as a framework for long term evaluation.

\section{References}

David, F. R. (2011). Strategic Management: Concepts \& Cases (13th ed.). Pearson Education, Inc. Upper Saddle River.

Dess, G. G., Lumpkin, G. T., Eisner, A. B., McNamara, G., \& Kim, B. (2012). Strategic Management: Text \& Cases (6th ed.). New York, NY: McGraw-Hill Irwin companies.

Fattah, D., \& Syaripudin, M. A. (2016).Philosophical Business Performance Competition on the Balance Scorecard Approach. International Journal of Economic Perspectives, 10(4), 541-551.

Haj, M., \& Ahmed, A. (2011).Strategic Educational Planning: Thought and Practice. Jordan, Amman: Dar Al Masirah.

Kaplan, R. S., \& Norton, D. P. (1992). The Balanced Scorecard-Measured that Derive Performance. Harvard $\begin{array}{lllll}\text { Business Review. } & \text { Retrieved } & \text { March } & 2614\end{array}$ fromhttp://org/1992/01/The-Balanced-Scorecard-Measures-that-Derive-Performance.

Khatib, A. (2001).University administration: A recent study. Jordan, Irbid: Hamada Foundation.

Pearce II, John A., \& Robinson, R. B. (2011). Strategic Management (12th ed.) Newyork, NY: McGraw-Hill Irwin companies, inc.

Saad, R. I., \& Daraghma, M. A. (2016).Using of the Balanced Scorecard for Performance Evaluation: Empirical Evidence from the Listed Corporations in the Palestine Exchange (PEX). International Journal of Business and Management, 11(3). http://dx.doi.org/10.5539/ijbm.v11n3p215

Sekaran, U., \& Bougie, R. (2010). Research Methods for Business: A Skill Building Approach (5thed.). United Kingdom, Chichester, West Sussex: John Willy \& Sons Ltd.

Vesty, G., \& Brooks, A. (2017). St George Hospital: Flexible Budgeting, Volume Variance, and Balanced Scorecard Performance Measurement. Issues in Accounting Education, American Accounting Association, 32(3), 103-116. https://doi.org/10.2308/iace-51588

\section{Copyrights}

Copyright for this article is retained by the author(s), with first publication rights granted to the journal.

This is an open-access article distributed under the terms and conditions of the Creative Commons Attribution license (http://creativecommons.org/licenses/by/4.0/). 